\title{
35. Research on Xanthurenic Acid. IV. Effect of Insulin on Tryptophan Metabolism
}

\author{
By Yashiro Kotake, M.J.A., Yahito Kotake (Jr.), and Masao Hishikawa \\ Biochemistry Department of Wakayama Medical College \\ and Takeo SAKAN and Masao YAMAGUCHI \\ Science and Engineering Department of Osaka City College \\ (Comm. March 12, 1953)

\section{Introduction}

It is already announced ${ }^{\left.1{ }^{2}\right)}$ that, when sodium salt of fatty acid and tryptophan were administered together to white rats following the prescription of Yahito Kotake and Inada, xanthurenic acid, which is an abnormal metabolite of tryptophan, is excreted, and the animals show pancreas diabetic symptoms. On the occasion, when a large amount of sodium salt of fatty acid is administered, after the research of Lepkovsky et al.: it is imagined that the white rat falls into acute vitamin $\mathrm{B}_{6}$ deficiency, and by our researches ${ }^{+)}$, it has become to be understood that vitamin $\mathrm{B}_{6}$ is probably necessary in the TCA. cycle or its attached reactions. Further we advanced our researches under the idea that there might be some relation between xanthurenic acid or its similar substances in vivo from tryptophan, and the sugar metabolic hormone insulin, which has the closest relation in occurring diabetes. Moreover, it can be understood from the research of Forker, Chaikoff $^{5)}$ that there is a relation between insulin and protein metabolism. That is, they discovered that the synthesis of skin protein is remarkably hindered in the pancreas extirpated dog, and that its ability is immediately recovered when insulin is administered.

\section{Experimental and Consideration}

(I) Experimental method.

As a control we used the male white rat ( $150 \mathrm{~g}$. body weight) which is administered orally tryptophan $0.1 \mathrm{~g}$. and butyrate $0.4 \mathrm{~g}$. together after the method of Yahito Kotake and Inada ${ }^{1)}$, and made in a condition to excrete enough xanthurenic acid in urine. Injecting insulin to this animal and collecting 24 hours urine, we made the following experiments. (In the following, we will name the control $\mathrm{C}$, and the insulin injected test urine $\mathrm{S}$, for conveniency.)

(II) Examination by paper-chromatography.

The previous management of the urine was done following the method of Neuberger et al. ${ }^{6}$ ) on examining the urine of pyridoxine 


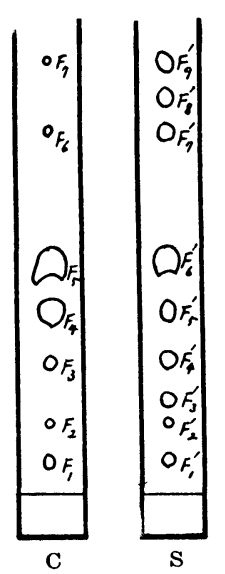

C: Control

S: Control + insulin

Fig. 1

deficient white rat. That is, after collecting and filtering the urine, mercuric acetate was added immediately and left one night, then its sedimented part was decomposed by passing $\mathrm{H}_{2} \mathrm{~S}$, and the surplus $\mathrm{H}_{2} \mathrm{~S}$ was driven away from the filtrate, and finally the whole liquid amount was all made equal to $1.0 \mathrm{cc}$. by concentrating the filtrate by reducing pressure at a low temperature, and then was used as test materials.

Primary developing method was used, the filter paper used being Toyo filter paper No. 2, the developing reagent butanol acetate (butanol: acetic acid: water $=4: 1: 1$ ), and the developing time 15 hours.

After development, 7 fluorescent spots in $\mathrm{C}$ and 9 in $\mathrm{S}$ were noticed by fluorescence test as seen in Fig. 1. The results of various color-presenting reaction tests of the main spots are shown in Table I.

Table I

\begin{tabular}{|c|c|c|c|c|c|c|c|c|c|c|c|}
\hline \multirow{2}{*}{ Color reaction } & \multicolumn{5}{|c|}{ C (Control) } & \multicolumn{6}{|c|}{$\mathrm{S}$ (Control + insulin) } \\
\hline & $\mathrm{F}_{3}$ & $\mathrm{~F}_{4}$ & $\mathrm{~F}_{5}$ & $\mathrm{~F}_{6}$ & $\mathrm{~F}_{7}$ & $F_{1}^{\prime}$ & $F_{5}^{\prime}$ & $\mathrm{F}_{6}^{\prime}$ & $\mathrm{F}_{7}^{\prime}$ & $\mathrm{F}_{8}^{\prime}$ & $\mathrm{F}_{9}^{\prime}$ \\
\hline Rf value & 0.32 & 0.43 & 0.50 & 0.71 & 0.89 & 0.32 & 0.43 & 0.50 & 0.71 & 0.80 & 0.89 \\
\hline Bratton-Marshall & - & + & - & + & + & - & + & - & + & + & + \\
\hline Ehrlich & + & - & + & - & - & + & - & + & - & - & - \\
\hline Pauly & + & - & + & - & - & + & - & + & - & - & - \\
\hline Millon & - & - & + & - & - & - & - & + & - & - & - \\
\hline $\mathrm{Fe}^{\cdots}$ & - & - & + & - & - & - & - & + & - & - & - \\
\hline Ninhydrin & + & + & - & - & - & + & + & - & - & - & - \\
\hline
\end{tabular}

From the Rf value and color-presenting reactions shown in Table $\mathrm{I}$, it is sure that, in Fig. $1, \mathrm{~F}_{5}$ of $\mathrm{C}$ and $\mathrm{F}_{6}^{\prime}$ of $\mathrm{S}$ are both xanthurenic acid.

And between these two spots of $\mathrm{F}_{5}$ and $\mathrm{F}_{6}^{\prime}$, quantitatively distinct difference was seen in color-presenting reaction. That is, in each of the reactions of Ehrlich, Pauly, Millon and $\mathrm{Fe}^{\cdots}$, which xanthurenic acid presents, the coloring degree of $F_{6}^{\prime}$ was, compared with that of $\mathrm{F}_{5}$, extremely weak and its area very small. This difference was, being observed in 6 cases, very clearly noticed. And by this colorpresenting reactions, there were cases in which $\mathrm{F}_{6}^{\prime}$, that is, xanthurenic acid, was unable to be proved. Its effecting mechanism cannot be directly presumed by this experiment, but it has come to be under- 
stood that insulin hinders the production of xanthurenic acid, which is an abnormal metabolite of tryptophan.

About the spots on the filter paper besides xanthurenic acid, it is now still under examination, but in the spots, of which the $R f$ value is larger than that of xanthurenic acid, $\mathrm{S}$ has in general a stronger tendency to increase than that of $\mathrm{C}$, and especially in $F_{\tau}$ and $F_{9}^{\prime}$, which can be decided as anthranilic acid, ${ }_{m \varepsilon}$ a normal product of tryptophan ${ }^{7}$, from Rf, fluorescence test, and color-presenting reactions etc., $F_{9}^{\prime 10}$ is far.greater in quantity, and 9 from this fact, it can be presumed that insulin has an effect to return the abnormal metabolism of tryptophan to normal.

(III) Quantitative determination.

It was noticed from experimental results of experimental (II), that insulin has a tendency to reduce the production of xanthurenic acid, but further, quantitative determination was done in many cases following the method of Miller, Baumann ${ }^{8}$, and confirmed the fact that insulin remarkably hinders the production of xanthurenic acid. Moreover, it was confirmed that, in order to lessen the production of xanthurenic acid mostly,

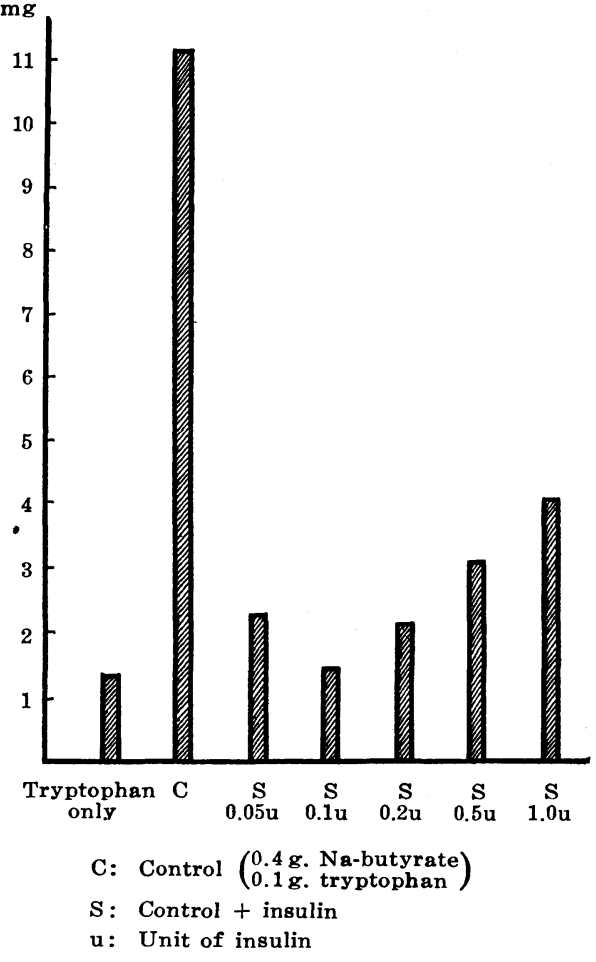

Fig. 2 an adequate amount of insulin injection is necessary. This quantitative determination results are shown in Fig. 2.

(IV) When an adequate amount of insulin is administered together with sodium salt of fatty acid and tryptophan, xanthurenic acid is remarkably reduced in the white rat urine as shown in the abovementioned experiment. And on this occasion, we were able to isolate a compound instead of xanthurenic acid from this urine (about $10 \mathrm{mg}$. per 1 white rat).

The nature of this compound is as following: m.p. $268-269^{\circ} \mathrm{C}$, Kretschy test and Jaffe test respectively positive.

From its m.p. or from Kretschy test and Jaffe test, it is similar to kynurenic acid, and though there are some unsatisfying points in the analytic results, ultra-violet part absorption spectrum examination of this compound was done with Beckman's photometer. Its result 
is as shown in Fig. 3.

Moreover, the result of the ultra-violet absorption spectrum examination upon kynurenic acid, a product of Roche Co., is shown in Fig. 4.

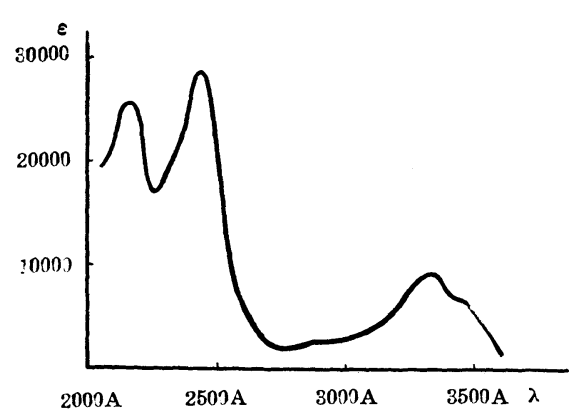

$\lambda_{\text {max. }}: 2150,2440,3320,3440 \mathrm{~A}$

m.p. : $268 \sim 269^{\circ} \mathrm{C} \quad \mathrm{pH}: 7.3$

Fig. 3. Crystal from urine

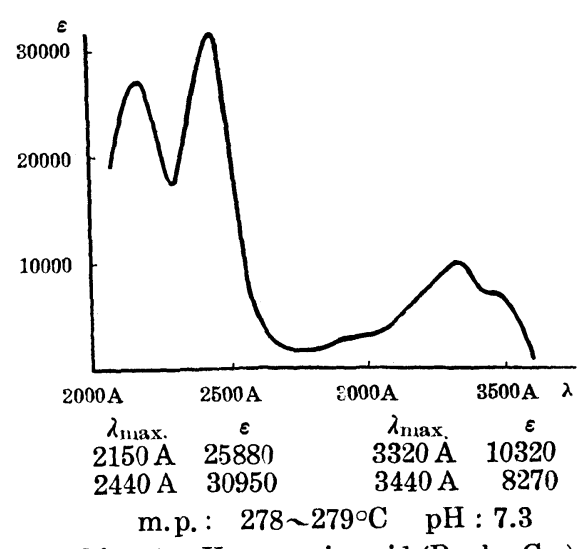

Fig. 4. Kynurenic acid (Roche Co.)

We think this compound may be decided as kynurenic acid. Further, to make it sure, we took the absorption spectrum of the ultrared part, and confirmed that it coincides with that of kynurenic acid (Fig. 5, 6).

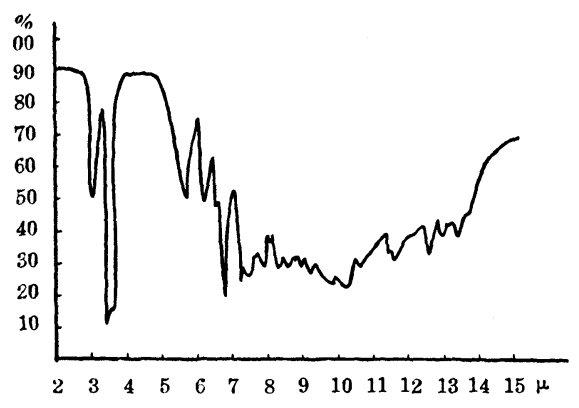

Fig. 5. Crystal from urine (in $\mathrm{MeOH}$ )

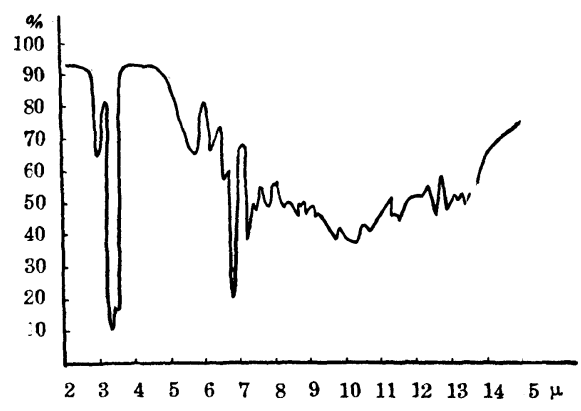

Fig. 6. Kynurenic acid (in $\mathrm{MeOH}$ )

This research is very interesting relating it to the research of Yashiro Kotake and Katashi Ichihara", in which it is said that kynurenic acid is only an end by-product of tryptophan, while it is non-poisonous and non-effective. Probably kynurenic acid is presumed to be the only non-poisonous metabolite with a quinoline nucleus, so it can be thought that the fact that diminishing in the production of xanthurenic acid and increase of kynurenic acid is due to a detoxication by insulin. Researches concerned to this are to be continued. 


\section{References}

1) Kotake, Y. (Jr.) and Inada, T. : Proc. Japan Acad., 28, 65 (1952).

2) Kotake, Y. (Jr.) and Tani, S.: Proc. Japan Acad., 28, 596 (1952).

3) Lepkovsky, S., Roboz, E., and Haagen-Smit, A.J.: J. Biol. Chem., 149, 195 (1943).

4) Hishikawa, M.: Unpublished.

5) Forker and Chaikoff : J. Biol. Chem., 188, 37 (1951); 196, 829 (1952).

6) Lalgliesh, Kn॰x, and Neuberger: Nature, 168, 20 (1951).

7) Nakayama, Y.: Med. J. Osaka, 38 (1937); 39 (1938). Kotake, Y. and Kotake, Y. (Jr.): Ditto, 41 (1942). Kotake, Y. (Jr.) and Honda, H. : Ditto, 41 (1942).

8) Miller, E.C. and Baumann, C.A.: J. Biol. Chem., 157, 551 (1945).

9) Kotake, Y. and Ichihara, K.: Z. physik. Chem., 195, 171 (1931). 